\title{
Original Research Psychotropic and psychoactive drugs and hospitalization rates in nursing facility residents
}

\author{
James W. COOPER, Megan H. FREEMAN, Christopher L. COOK, Allison H. BURFIELD.
}

\begin{abstract}
$^{*}$
The purpose of this study was to determine if there were any differences in hospitalization rates due to total psychoactive drug "load" between those using and not or formerly using psychotropic and psychoactive medications in a skilled nursing facility; to determine if the diagnosis of dementia and the change in use and load of psychotropic and psychoactive drugs influenced hospitalization rates. Methods: An observational retrospective cohort study was conducted of patient chart, facility disposition changes and consultant pharmacist reports data from a skilled nursing facility of more than 100 beds. Some177 patients resident for 30 or more days over a 19 month period of 2978 patientmonths data were tabulated. A monthly repeatedmeasures assessment method that incorporated all conditions, diseases and medication changes was done on each resident to determine patient demographics, medication usage, and hospitalizations.
\end{abstract}

Results: The rates of hospitalization ranged from 0.04 to 0.07 per patient/month for any psychoactive usage in those with and without dementia as a diagnosis. The rate of hospitalization during the study period for those with no current psychotropic nor regular psychoactive usage was 0.02 and $0.03 / \mathrm{pt}$./month for those respectively with and without the diagnosis of dementia, yet $86 \%$ of this sample had used psychotropics or other psychoactive drugs before the period of observation.

Conclusion: Preliminary evidence is offered that suggests psychotropics and psychoactive drugs and the total "load" of these drugs may be associated with an increase in the rate and risk of all hospitalizations within a single skilled nursing facility.

\footnotetext{
James W. COOPER. RPh, PhD, BCPS, CGP, FASHP, FASCP. Emeritus Albert W. Jowdy Professor and Consultant Pharmacist, College of Pharmacy, University of Georgia, Athens, GA (USA).

Megan H. FREEMAN. PharmD, BCPS. Manager of Clinical Pharmacy Services and Director, Pharmacy Practice Residency, Northside hospital , Atlanta, GA (USA).

Christopher L. COOK. PharmD., PhD. Clinical Associate Professor, Department of Clinical and Administrative Pharmacy, College of Pharmacy, University of Georgia, Athens, GA (USA).

Allison H. BURFIELD. RN, MSN. Doctoral student and Provost Fellow, School of Nursing, University of Central Florida, Orlando FL (USA).
}

Keywords: Psychotropic Drugs. Skilled Nursing Facilities. Hospitalization. United States.

\begin{abstract}
RESUMEN
El propósito de este estudio fue determinar si había diferencias en las tasas de hospitalización debido a la carga de agentes psicoactivos en una residencia de ancianos entre los que utilizan psicotropos con los que no o los habían usado antes; determinar si el diagnóstico de demencia y el cambio en el uso y carga de medicamentos psicotrópicos y psicoactivos influye en las tasas de hospitalización. Métodos: Se realizó un estudio observacional de una cohorte retrospectiva de historiales de pacientes, cambios de situación en la residencia e informes del farmacéutico en una residencia de ancianos avanzada de más de 100 camas. Se tabularon datos de 177 residentes de 30 días o más durante un periodo de 19 meses, tabulándose un total de 2978 pacientes-mes. Se realizó un método de medidas repetidas de cambios de situaciones clínicas, enfermedades y medicación, para determinar la demografía, el uso de medicamentos y las hospitalizaciones de cada paciente.

Resultados: Las tasas de hospitalización variaron de 0,04 a 0,07 por paciente/mes para el uso de cualquier psicoactivo en los que tenían o no diagnóstico de demencia. La tasa de hospitalización durante el periodo de estudio para los que no usaban actualmente psicotropos o psicoactivos fue de 0,02 y 0,03 por paciente/mes para los que tenían diagnóstico de demencia y los que no, respectivamente, aunque el $86 \%$ de esta muestra había usado psicotropos o psicoactivos antes del periodo de observación.

Conclusión: Se ofrece evidencia preliminar que sugiere que los psicotropos y psicoactivos y la carga total de estos medicamentos puede estar asociada al aumento en la tasa y el riesgo de hospitalizaciones en una residenciad e ancianos avanzada.
\end{abstract}

Palabras clave: Psicotropos. Residencias de ancianos avanzadas. Hospitalización. Estados Unidos.

\section{(English)}

\section{INTRODUCTION}

Psychotropic drugs have been shown to be a significant predictor of nursing home placement 
from a non-acute geriatric hospital. ${ }^{1-3}$ The relation of psychotropic or psychoactive drug use and allcause hospitalizations in nursing facility residents has not been found in the literature to date, using the keywords psychotropics, psychoactives, and hospitalization from nursing facilities. The influence of psychoactive and psychoactive drugs on nursing home outcomes needs to be delineated. The purpose of this study was to determine if there are any difference in hospitalization between prior users, users and current non-users of psychotropic and psychoactive drugs in those with and without the diagnosis of dementia.

\section{METHODS}

Patient records and disposition reports and consultant pharmacist monthly reports were gathered via a retrospective nested case-control cohort study.

The setting was a rural, greater than 100-bed skilled nursing facility. The study was approved under the Pharmacoepidemiology Project of the Human Subjects Committee of the Institutional Review Board of the University with a waiver of consent as all information gathered was deemed to be in the routine practice of facility clinicians and anonymity of site and patients was assured. The administration of the skilled nursing facility also approved the study under the same considerations. Each patient's chart for a nineteen month period during 1996-7 was reviewed. Monthly patient status or disposition reports for the skilled nursing facility were also reviewed. A data base storage and retrieval system was developed. Access was available to all records before and after the study period. Progress and nurses notes, medication orders, medication administration records, monthly hospitalization reports, resident status and consultant pharmacist drug regimen review reports.

Psychotropics were defined as anxiolytics, hypnotics, antipsychotics and antidepressants and considered to be used on a regular daily basis. Psychoactives were classified as cholinesterase inhibitors, sympatholytic antihypertensives, sedating antihistamines, anticonvulsants, metoclopramide, opioid analgesics and muscle relaxants, and had to be used at least once weekly to be considered active usage.
Consultant pharmacist monthly drug regimen review routinely recommended changes to include tapering to discontinuance, drug changes, minimization of psychoactive load and simplification of the medication regimen. An further assessment of each patient using psychoactives was made by the consultant pharmacist by physical observation of patient alertness and orientation to time, place and person usually with the charge nurse for the patient on that unit, especially when multiple psychotropics, excessive doses of any psychotropic or multiple psychoactives, a fall or daytime sedation or agitation episodes occurred. Hospitalizations were noted from both patient charts and monthly status reports of the facility. Hospitalization rate was defined as the number of hospitalizations per resident per month. Means rates of hospitalizations between both demented and non-demented residents and those using and not using psychotropics or other psychoactive drugs during the study period were compared using the t-test statistic. The null hypotheses were that there would be no differences in hospitalizations between users and those tapered to non-use or no use of psychotropic and/or psychoactive drugs, in those with and without the diagnosis of dementia.

\section{RESULTS}

One hundred seventy-seven patients, predominantly females residing for 30 or more days were included in the study (table 1) over 2978 patient-months. The groups using and not presently using psychotropics and psychoactives appeared to be similar in terms of problems, age, sex, and history of hospitalization as well as use of psychotropic medications. Table 2 indicates that hospitalized patients were found to have a higher current psychotropic and psychoactive drug "load" than their non-hospitalized counterparts. The total number of hospitalizations was 137 in 77 residents. The difference in the rate of hospitalizations for 130 residents taking psychotropics or psychoactives (113, 0.87/patient) and those 47 not presently taking psychotropics nor psychoactive medications (24 or 0.51 patient or) was statistically significant $(p<0.05)$. It is important to note that 40 of these 47 patients had a history of psychotropic and/or other psychoactive usage and had those medications tapered to discontinuance before the study period.

\begin{tabular}{|l|c|c|}
\hline \multicolumn{2}{|l|}{ Table 1. Patient Demographics } & Without Dx Dementia $(\mathrm{n}=77)$ \\
\hline Total Number (177) & Dementia $(\mathrm{n}=100)$ & 1268 \\
\hline $\begin{array}{l}\text { Total Patient-months from start to } \\
\text { end of study (3229 or 18.2 } \\
\text { months/patient) }\end{array}$ & 1710 & $78 ; 22$ \\
\hline Gender \% female;male & $79 ; 21$ & $80.2(\mathrm{SD}=11.3)$ \\
\hline $\begin{array}{l}\text { Age (mean+/-SD*) Overall-81.8 } \\
\text { years (+/-10.7) }\end{array}$ & $83.0(\mathrm{SD}=9.7)$ & $6.0(\mathrm{SD}=1.8)$ \\
\hline No. of Problems/pt. (mean +/- SD & $6.2(\mathrm{SD}=2.1)$ & $6.9(\mathrm{SD}=2.6)$ \\
\hline Total no. meds/pt. mean (SD) & $6.3(\mathrm{SD}=2.4)$ & 86.3 \\
\hline $\begin{array}{l}\% \text { with Hx }{ }^{* *} \text { of psychotropic or } \\
\text { psychoactive Usage }\end{array}$ & 87 & 30.7 \\
\hline $\begin{array}{l}\% \text { with H* }{ }^{* *} \text { of Hospitalization } \\
\text { prior to nursing facility admission }\end{array}$ & 29.4 & \\
\hline${ }^{*} \mathrm{SD}=$ standard deviation ${ }^{* *} \mathrm{DX}=$ diagnosis, $\mathrm{Hx}=$ history ( From facility admission records) \\
\hline
\end{tabular}




\begin{tabular}{|l|c|c|}
\hline \multicolumn{3}{|c|}{ Table 2. Psychoactive/Psychotropic Drug Load and Hospitalizations for all patients } \\
\hline \multicolumn{1}{|c|}{ Drug Load } & Hospitalized & Non Hospitalized \\
\hline Psychotropic/Psychoactive & $4.66 /$ patient $^{*}$ & $3.19 /$ patient \\
\hline Psychotropic only & $2.10 /$ patient $^{*}$ & $1.65 /$ patient \\
\hline *between-group; $p<0.05$ via t-test. & & \\
\hline
\end{tabular}

These discontinuations were the results of ongoing active interventions by a consultant pharmacist, nursing staff and attending physicians to reduce psychotropic and overall psychoactive drug use. ${ }^{4-7}$

Multiple psychoactive only (2-9/pt) as a class had 43 patient months of use with five hospitalizations in three patients $(0.6 / \mathrm{pt}$. or $0.105 / \mathrm{pt} /$ month). There were 251 patient months of single psychoactive use (no psychotropics) with 12 hospitalizations in 20 patients (0.6/pt.) and 12/251=0.047/pt./month).

Hospitalization rates were also examined after classifying patients in groups, based on the diagnosis of dementia in table 3 . Of the 100 patients with dementia, $42 \%$ were hospitalized. Of the 77 patients without dementia, $45 \%$ were hospitalized over the study period. The crude hospitalization rate per 42 patients with dementia who were hospitalized is $61 / 42$ or 1.45 per patient who were hospitalized. The crude rate for the non-demented population hospitalized is $76 / 35$ or 2.17 per hospitalized patient

In those with and without dementia the rate of hospitalization doubled in those using psychotropics and multiple psychoactive drugs. Hospitalization admission diagnoses were primarily for falls, dehydration and infections (table 4) and113 of the 137 admissions were in patients using psychotropic drugs. The null hypothesis was rejected, in that there were significant differences in the rates and hospitalizations between those using and not using psychotropic and psychoactive drugs. There was a correlation of the hospitalization rate with psychotropic and psychoactive drug load (or between agents in a particular drug class, e.g., antipsychotics. There was apparently fewer hospitalizations in those not presently using psychotropic or other psychoactive drug therapy during the study period.

\begin{tabular}{|l|c|c|}
\hline \multicolumn{2}{|c|}{ Table 3- Hospitalization Rates by Drug Load in Patients with and without Dementia } \\
\hline & Patients with Dementia & Patients without Dementia \\
\hline Psychotropic/psychoactive Use & $0.04 /$ patient/month* & $0.07 /$ patient/month* \\
\hline No Psychotropic/psychoactive Use & $0.02 /$ patient/month & $0.03 /$ patient/month \\
\hline${ }^{*}$ between-group; $p<0.05$, via t-test & \\
\hline
\end{tabular}

\begin{tabular}{|c|c|c|c|c|c|}
\hline \multirow[t]{2}{*}{ Reasons } & \multicolumn{2}{|c|}{ Patients w/ Dementia $(n=100)$} & \multicolumn{2}{|c|}{ Patients w/o Dementia $(n=77)$} & \multirow[t]{2}{*}{ Total } \\
\hline & $+(n=78)$ & $-(n=22)$ & $+(n=52)$ & $-(n=25)$ & \\
\hline Dehydration & 6 & - & 10 & 7 & 23 \\
\hline Fall & 11 & - & 5 & 2 & 18 \\
\hline URTI & 4 & 3 & 7 & 1 & 15 \\
\hline Urinary tract infection & 6 & 1 & 4 & 2 & 13 \\
\hline LRTI & 4 & 1 & 7 & 1 & 13 \\
\hline Chest pain & 6 & - & 6 & - & 12 \\
\hline Surgery & 1 & - & 6 & 2 & 9 \\
\hline Stroke & - & 1 & 5 & - & 6 \\
\hline Psychiatric evaluation & 5 & - & 1 & - & 6 \\
\hline Acute heart failure & 4 & - & - & 1 & 5 \\
\hline Prolapsed rectum & 4 & - & - & - & 4 \\
\hline Seizures & & - & 3 & - & 3 \\
\hline Nausea and vomiting & 1 & - & 1 & - & 2 \\
\hline Low plasma glucose & - & - & 1 & - & 1 \\
\hline Choking & - & - & 1 & & 1 \\
\hline Hematuria & - & - & - & 1 & 1 \\
\hline Hemorrhage & - & - & - & 1 & 1 \\
\hline Hematemesis & 1 & - & - & - & 1 \\
\hline Unknown & 2 & - & 1 & - & 3 \\
\hline Subtotals & 55 & 6 & 58 & 18 & 137 \\
\hline
\end{tabular}

The specific agents used during the 1996-7 study period were as follows. The preponderance of psychotropics were conventional antipsychotics (predominantly haloperidol, $166 \mathrm{pt} /$ months, average dose $2.5 \mathrm{mg} / \mathrm{day}$ ) and thioridazine (244 pt.months, average dose $40.4 \mathrm{mg} /$ day), and the atypical antipsychotic risperidone (82 pt.months, average dose $3.4 \mathrm{mg} / \mathrm{day}$ ). Anxiolytics included buspirone ( 374 pt.months, average dose $32.7 \mathrm{mg} /$ day) and the intermediate to longer-acting anxiolytic and hypnotic benzodiazepines diazepam (130 pt. months, average dose $6 \mathrm{mg} /$ day), lorazepam (169 pt.months, average dose $1.5 \mathrm{mg} /$ day, alprazolam (71 pt. months, mean dose $1.2 \mathrm{mg} / \mathrm{day}$ ), temazepam (58 pt. months, average dose $4.6 \mathrm{mg} /$ day), chlorazepate (33 pt.months, average dose $8.6 \mathrm{mg} /$ day), clonazepam (25 pt.months, average dose $1.4 \mathrm{mg} /$ day) and the shorter-acting oxazepam (46 pt.months, average dose $36.7 \mathrm{mg} / \mathrm{day}$ ). 
Antidepressants include tricyclic, atypical and SSRI antidepressants. Tricyclics and atypicals included amitriptyline (360 pt.month, average dose $37.3 \mathrm{mg} /$ day), trazodone (126 pt.months, average dose $62.1 \mathrm{mg} /$ day) doxepin (66 pt.months, average dose $68.2 \mathrm{mg} /$ day), imipramine (37 pt.months, average dose $42.4 \mathrm{mg} /$ day), nortriptyline (16 pt.months, average dose $50 \mathrm{mg} /$ day). The SSRIs included paroxetine (240 pt. months, mean dose $18.2 \mathrm{mg} /$ day), sertraline (163 pt.months, average dose $55 \mathrm{mg} /$ day) and fluoxetine (72 pt.months, average dose $17.2 \mathrm{mg} /$ day). The hypnotics were zolpidem (273 pt.months, average dose $5.4 \mathrm{mg} /$ day) and flurazepam (21 pt.months, mean dose $22 \mathrm{mg} /$ day).

The predominant psychoactives used on a regular schedule or PRN once or more per week basis were the cholinesterase inhibitor donepezil, narcotic analgesics (propoxyphene, hydrocodone), metoclopramide, anticonvulsants (phenytoin, phenobarbital, and carbamazepine), muscle relaxants (carisprodal, orphenadrine), sedating antihistamines (chor- and brompheniramine, meclizine, diphenhydramine, triprolidine, hydroxyzine), antisecretory antihistamines (cimetidine, ranitidine) and centrally-acting antihypertensives (methyldopa, clonidine, guanethidine). The relative hospitalization rates between agents in a particular pharmacologic class were not examined in this study. The total problems, medications per patient and both prior psychotropic/psychoactive usage and hospitalization history (table 1) were not significantly different between groups.

Additionally the rate of hospitalization for those 47 not using either drug group (0.57/pt.) during the study period yet 40 of 47 had a history of usage was significantly lower than all other 130 residents $(0.87 / \mathrm{pt})$. All of these patients had had active consultant pharmacist and nursing interventions to decrease the total "load" and doses and/or discontinue these drugs. These findings combined with the history of changes to include tapering and discontinuance in this group suggests that psychotropic and psychoactive drugs may have been a contributing factor to the higher rate of hospitalization in this preliminary investigation.

\section{DISCUSSION}

A prior study of physical and pharmacologic restraint of 307 nursing home patients with dementia showed that $4345 \%$ of nursing home residents were given pharmacologic restraints and that the patient with physically abusive behavior, frequent family visits and severe cognitive impairment were more likely to receive pharmacologic restraints. ${ }^{2}$ An earlier one year study of 33,351 Illinois nursing home residents found that $60 \%$ received at least one psychotropic medication during that year. ${ }^{3}$ The effects of the psychotropics on agitation and interventions on falls, injuries and hospitalization costs ${ }^{4-7}$ were previously studied in this population. The 1987 and 1990 Omnibus Budget Reconciliation Acts (OBRA) provisions regarding appropriate utilization of psychotropic drugs mandate at least 2 to 3 tapering attempts of anxiolytics (except buspirone), hypnotics and antipsychotic psychotropics within the first 6 to 12 months of placement within a nursing facility unless there is a history of patient exacerbation of dementia or other neuropsychiatric diagnosis on tapering attempt.

The present retrospective study offers preliminary evidence that psychotropic and psychoactive drugs and the total "load" of these medications may be associated with an increase in the risk of hospitalization in patients with a similar history of hospitalization and psychotropic and psychoactive drug exposure, irrespective of the diagnosis of dementia. There was no attempt made to determine differences between specific agents in each psychotropic class. Larger prospective controlled studies will be needed to verify these findings. An earlier study of adverse drug reaction related hospitalizations from nursing facilities found that psychotropic-related falls were second only to NSAID gastropathy as the most common ADR hospitalization of elderly nursing facility residents. ${ }^{8}$

This study also raises the question as to whether or not all-cause hospitalizations, some of which may not seem associated with psychotropics or psychoactive medications, (e.g., dehydration and infections) may have some degree of association with these drugs A study of behavioral symptoms and the administration of psychotropic drugs to aged patients with dementia in nursing homes and in acute geriatric wards found that $87 \%$ were on at least one psychotropic; $66 \%$ took at least two, 36\% at least three and $11 \%$ were taking four or more psychotropics. ${ }^{9}$ The finding that in at least one double-blind trial of psychotropics versus behavioral management techniques in dementia that the conventional psychotropics haloperidol and trazodone actually increased agitation, falls and behavioral management problems. ${ }^{10}$

Adverse outcomes associated with inappropriate drug use in nursing homes have recently been published. ${ }^{11,12}$ In view of the recent addition of a "black box" warning to all atypical antipsychotics that suggests there may be a higher death rate in older adults using these agents for dementia-related agitation it may be wise to judiciously use these psychotropic agents solely for dementia-related agitation. $^{13}$ Additionally, a 22,890 patient retrospective 1994-2003 study of patients 65 and older found that conventional antipsychotics were associated with a significantly higher adjusted risk of hospitalization and death than were the atypical antipsychotics at all intervals studied and in all subgroups, but especially when first started. ${ }^{14}$

There were active interventions by the consultant pharmacist, nursing staff and attending physicians to taper and discontinue psychotropic and psychoactive medications throughout this study and as a continuation of earlier studies. ${ }^{4-7}$

The effect of using lower doses of multiple psychotropics as a possible method of reducing adverse drug reactions to higher doses of single agents was not considered in this study .A final 
consideration that deserves consideration is that the psychotropic "load" has also been suggested to be associated with the rate of falls in this same population over the same study period. ${ }^{15}$

\section{Limitations of the study}

The limitations of this study were that it was in only one nursing facility with a small number of patients and for a relatively short period of time. As such these results should be considered preliminary, anecdotal and only suggestive of an association with psychotropic and psychoactive load and hospitalizations. Larger multi-site studies are needed to verify these findings. Until these studies are done it would be premature to extrapolate these results to a larger long-term care population.

\section{CONCLUSIONS}

Psychotropic and psychoactive use appeared to be associated with an increased rate of hospitalizations. A patient's hospitalization rate doubled when they were using psychotropic and psychoactive drugs, irrespective of the diagnosis of dementia, total problems and other medications.
There was also a higher utilization rate of these drugs in the group hospitalized than in those not hospitalized while using these drugs. Therefore, a high priority of attending physicians and affiliated clinicians to include nurse practitioners and physician's assistants, as well as nurses and consultant pharmacists in the nursing facility environment should be to decrease patients' inappropriate psychotropic and psychoactive drug loads when conducting patient visits, nursing assessments and monthly drug regimen reviews. This study suggests that psychotropic load interventions may lead to a decrease in hospitalizations among long term care facility residents.

\section{ACKNOWLEDGMENTS}

This study was supported in part by an unrestricted grant through the University of Georgia College of Pharmacy.

\section{CONFLICT OF INTEREST}

None declared.

\section{References}

1. Aditya BS, Sharma JC, Allen SC, Vassallo M. Predictors of a nursing home placement from a non-acute geriatric hospital. Clin Rehabil 2003: 1:108-13.

2. Sloane PD, Mathew LJ, Scarborough M, Desai JR, Koch GG, Tangen C. Physical and pharmacologic restraints of nursing home patients with dementia. JAMA 1991;265:1278 82.

3.Buck JA. Psychotropic drug practice in nursing homes. J Am Geriatri Soc 1988;36:409 18.

4. Cooper JW, Cobb HH, Burfield AH. Buspirone conversion effect on falls, injuries, behavior and costs in a rural geriatric nursing home population. Consult Pharm 2001; 16(4):358-63.

5. Cooper JW. Consultant pharmacist assessment and reduction of fall risk in nursing facilities. Consult Pharm 1997; 12: 1294-304.

6. Cooper JW. Consultant pharmacist assessment of fall injury incidence and costs within a nursing facility. Consult Pharm 1997; 12: 1305-9.

7. Cooper JW. Reducing falls among patients in nursing homes. JAMA 1997;278: 1742.

8. Cooper JW. Adverse drug reaction-related hospitalizations of nursing facility patients: a 4-year study. South Med J 1999; 92:485-90.

9. Pitkala KH, Laurila JV, Strandberg TE, Tilvis RS. Behavioral symptoms and the administration of psychotropic drugs to aged patients with dementia in nursing homes and in acute geriatric wards. Int Psychogeriatri 2004:16(1): 61-74.

10. Teri L, Logsdon RG, Peskind E, Raskind M, Weiner MF, Tractenberg RE, Foster NL, Schneider LS, Sano M, Whitehouse P, Tariot P, Mellow AM, Auchus AP, Grundman M, Thomas RG, Schafer K, Thal LJ; Alzheimer's Disease Cooperative Study. Treatment of agitation in Alzheimers's Dementia: a randomized placebo-controlled clinical trial. Neurology. 2000;55(9):1271-8.

11. Perri M 3rd, Menon AM, Deshpande AD, Shinde SB, Jiang R, Cooper JW, Cook CL, Griffin SC, Lorys RA. Adverse outcomes associated with inappropriate drug use in nursing homes. Ann Pharmacother 2005;39(3):405-11.

12. Lau DT, Kasper JD, Potter DE, Lyles A, Bennett RG. Hospitalization and death associated with potentially inappropriate medication prescriptions among elderly nursing home residents. Arch Int Med 2005; 165:68-74.

13. Professional Package Insert materials for clozapine, olanzapine, quetiapine, risperidone, ziprasidone and aripiprazole, 2007.

14. Wang PS, Schneeweiss S, Avorn J, Fischer MA, Mogun H, Solomon DH, Brookhart MA. Risk of death in elderly users of conventional vs. atypical antipsychotic medications. N Engl J Med 2005;353:2335-41.

15. Cooper JW, Horner MR, Cook CL, Burfield AH. Psychotropic and Psychoactive Drug Load Assessment and Falls in Nursing Facility Residents. Consult Pharm, 2007: 22:483-9. 